\title{
On Heidegger's Sense of Understanding in Terms of Existentialism
}

\author{
Shao-hua ZHANG \\ School of Foreign Languages, Henan Institute of Engineering, Zhengzhou, China \\ 32453091@163.com
}

Keywords: Heidegger, Sense of understanding, Interpretation, Forestructure of understanding .

\begin{abstract}
Any kind of intelligible actions performed by us is made of some use of our understanding of being which has already been there beforehand; otherwise there will be no such intelligible actions. If there are no intelligible actions in us, the meaning of us as human beings is completely lost, because we as human beings living or existing in the world only have one basic state which is characterized by Heidegger's sense of being-in-the-world. Being-in-the-world means we are always somewhat intelligible in the world, and this intelligibility is made up of our understanding of being.
\end{abstract}

\section{Introduction}

The following remarks by Heidegger just seem to refer to "the instructor" and "the child" respectively:

Whenever one cognizes anything or makes an assertion, whenever one comports oneself towards entities, even towards oneself, some use is made of 'Being'; ... It makes manifest that in any way of comporting oneself towards entities as entities - even in any Being towards entities as entities - there lies a priori an enigma. The fact that we already live in an understanding of Being.... Inquiry itself is the behavior of a questioner, and therefore of an entity, and as such has its own character of Being. When one makes an inquiry one may do so 'just casually' or one may formulate the question explicitly” (BT, 23/24-25; italics added).

That is to say, whenever we comport ourselves towards something as something, even towards ourselves, we are always guided by "the fact that we already live in an understanding of Being". It is our "understanding of being" that directs our comporting ourselves towards something. Can't we, then, say that "understanding of being" is just a kind of light which in advance illumines those entities towards which we are able to direct our behavior? Isn't it that the light of "understanding of being" which illumines something as something arises from us? Can't we say that it is the "understanding of being" of entities that determines "who we are" and "what entities they are"? Isn't it that "what entities they are" determines "who we are", because, on Heidegger's view, the "are" (being) is always the "are" (being) of entities (BT, 29)? Just recalling "Dasein is an entity which, in its very Being, comports itself understandingly towards that Being" (BT, 78). Therefore, any kind of intelligible actions performed by us is made of some use of our understanding of being which has already been there beforehand; otherwise there will be no such intelligible actions. If there are no intelligible actions in us, the meaning of us as human beings is completely lost, because we as human beings living or existing in the world only have one basic state which is characterized by Heidegger's sense of being-in-the-world. Being-in-the-world means we are always somewhat intelligible in the world, and this intelligibility is made up of our understanding of being. 


\section{The Similarity among Being, Understanding and Intelligibility}

Here, being, intelligibility, and understanding are largely commensurable and can be exchanged in their use. Therefore, when we intelligibly comport ourselves to something, then the thing towards which we comport ourselves must be as it is in that mode of an intelligible comporting. This fact of understanding of being belonging to our being-in-the-world drives us to make explicit the question of what "being" means in terms of its meaning, because this is the inherent tendency which our understanding of being as a kind of competence possesses. That is why we are never satisfied with merely being-present-at-hand of something but always tend to make up of and look for a more meaningful presence of such being-present-at-hand of something which is available in our getting it used. "Out of this understanding arise both the explicit question of the meaning of Being and the tendency that leads us towards its conception. We do not know what 'Being' means. But even if we ask, "What is 'Being'? We keep within an understanding of the 'is', though we are unable to fix conceptually what that 'is' signifies. ... But this vague average understanding ofBeing is still a Fact"(BT, 25). That is to say, no matter how our understanding of being is vague, dim, and amorphous, yet when the act of an understanding takes place it means at the same time a being has been understood, because such taking place of understanding as a fact always keeps itself within an understanding of 'is' . This is the reason why when Heidegger talks about the conception of "understanding" he always means "an understanding" of "Being".

Speaking of literature, one kind of experience cannot be denied. When we experience a work of literature, the world provided by it seems to transform our own, it takes over, and for a moment, it is believed as self-enclosed, self-sufficient. It needs no measure outside of itself, and it is surely not to be checked against a copy of reality. How is it possible to reconcile with the assertion that the work of literature presents a world fully continuous with our own? In the light of what has been expounded, the justification must be fundamentally basic, that is, ontological: when we see a great work of literature and enter its world, we do not leave our understanding of being as being-in-the world alone as if we have "come home"; rather, we just find our being in the image, form and content of the work of literature in our own understanding of being. The author of the work has not conjured up an enchanted world which may be purely imaginable, it is we who experience the work that create this world in which we live, move, and have our being. Like the enchanting shell in the child's understanding mentioned earlier, the transformation of the shell is really a transformation of the truth of being. The shell does not give aesthetic pleasure but discloses being in the first instance. Understanding of a work of literature does not come through methodically cutting and dividing it as an object, or through isolating form from content; it comes through openness to being, and to responding to the question put to us by the work. Based upon our being-in-the-world, we let a work of literature present us with a world, which we are not to reduce to our own. We only understand a work of literature because we are already participating in the structure of self-understanding which makes the work of literature what it is, as the truth of being.

\section{The Relationship between Understanding and Being}

Here, a question will naturally turn up: "What is really the relationship between 'understanding' and 'Being'?" Perhaps the preposition "within" can provide us with an answer, but "within" has an ambiguity of its own. Reading through Heidegger's Being and Time, we feel that the preposition "of" in the phrase "understanding of Being" is probably much richer than "within". 
In sum, the word "of" can signify the following relationships: 1. to indicate a point of reckoning; 2. to indicate origin or derivation; 3 . to indicate the cause, motive, or reason; 4 . to indicate the component material, parts, or elements or the contents; 5 . to indicate the whole; 6 . to indicate being about; 7. to indicate belonging or possession; 8. to indicate a particular example belonging to the class denoted by the preceding noun; 9 . to indicate apposition; 10 . to indicate the object of an action denoted or implied by the preceding noun; 11 . to indicate a characteristic or distinctive quality or possession. Although the word "of' undertakes those eleven relationships, it nevertheless always foregrounds points $2,4,5,6,7,9$, and 11 . We make explicit the relationships between "understanding" and "Being" just for the sake of returning to the most primordial structure of Dasein's being-in-the-world. Taking being-in-the-world as a unitary phenomenon into consideration, we find that "understanding" or "being" must be rooted in the world but not nowhere or worldlessness. Furthermore, being-in-the-world as the most fundamental condition for understanding to take place means that understanding must operate in a fabric of relationships which are located in the lifeworld. That is, understanding is constituted in an interaction of Dasein's being-alongside and being-with-others.

Just like Heidegger's existential analytics of Dasein carried on the level of ontology, the conception of understanding has also been raised up (put down) to the level of ontology. In Heidegger's treatises, understanding is not analyzed on the level of ontics, that is, not reified into concrete ways, but anatomized in the most basic, fundamental, and constitutive sense, which is proved to be the ultimate foundation for all empirical understandings (interpretations). "For Heidegger, the conception of understanding is the power to grasp one's own possibilities for being, within the context of the lifeworld in which one exsits" (Palmer, 1969: 131). Therefore, it is "a mode or constituent element of being-in-the-world. ... It is not an entity in the world but rather the structure in being which makes possible the actual exercise of understanding on an empirical level" (ibid).

\section{Understanding Equiprimordial with State-of-mind}

To connect "understanding" with "state-of-mind" in an equiprimordial sense is the necessary consequence of the existential-ontological analysis of understanding. As Heidegger observes, 'Understanding of being is itself a definite characteristic of Dasein's Being. Dasein is ontically distinctive in that it is ontological.... What we have in mind in speaking of Dasein's 'Being-ontological' is to be designated as something 'pre-ontological'. It does not signify simply 'being-ontical', however, but rather 'being in such a way that one has an understanding ofBeing' "(BT, 32; italics as in original). Here exists a covert clue that understanding must be accompanied by some state-of-mind. "That kind ofBeing towards which Dasein can comport itself in one way or another, and always does comport itself somehow, we call existence.... Dasein always understands itself in terms of its existence - in terms of a possibility of itself: to be itself or not itself' (BT, 32-33). Here the clue that leads understanding to state-of-mind becomes even more explicit. Then we read, 'the 'essence' of this entity (Dasein) lies in its 'to be'. Being-what-it-is must, so far as we can speak of it at all, be conceived in terms of its Being. ... The term 'existence', as a designation ofBeing, will be allotted solely to Dasein” (BT, 67) under the title of "the Theme of the Analytic of Dasein". Heidegger goes on, "understanding is the existential Being of Dasein's own potentiality-for-Being; and it is so in such a way that this Being discloses in itself what its Being is capable of' (BT, 184). At this 
point, we finally get to know that understanding here is treated as well as Dasein's some state-of-mind which is in turn regarded as Dasein's competence for its "to be", for its "being-possible". "To be" or "being-possible" means possibilities for being which is substituted for "Being-there", and "Being-there" is fundamentally the character of Dasein or another name for Dasein. This character of "Being-there" is already a state-of-mind, for it has been a state-of-mind which has already been thrown there in such-and-such a manner. Being-thrown is the most primordial state of Dasein. Therefore, to regard "Being-there as an understanding" is no more than to regard some state-of-mind as an understanding. In a word, Dasein, understanding, and state-of-mind are so closely related that they can explicate one another. From an existential-ontological point of view, Dasein or the human being has been thus defined and expressed by its understanding of being and state-of-mind which are co-original or equiprimordial. Naturally, when Heidegger talks about "understanding" again, he adopts the section title "Being-there as Understanding". At the very beginning of this section, Heidegger connects "understanding" with "state-of-mind": "State-of-mind is one of the existential structures in which the Being of the 'there' maintains itself. Equiprimordial with it in constituting this Being is understanding... . Understanding always has its mood" (BT, 182). We can thereby go on saying "state-of-mind is nothing but a kind of understanding of being".

\section{Conclusion}

Dasein or the human being has "understanding" and "state-of-mind" as its co-original constituents. Dasein essentially consists in its existence which is determined by its existing, by its 'to be', by its Being-possible. Therefore, understanding and state-of-mind again are the constitutive items ofDasein's or the human being's existing. Understanding and state-of-mind must inevitably have their basis of the lifeworld, the world of "being-in-the-world". As a state-of-mind, understanding is not a transcendental apprehension or comprehension as a gift given by God; it is constructed in the being-in-the-world, formed in a fabric of relationships of the lifeworld. Based upon this being-in-the-world, understanding in its everyday life, proximally and for the most part, does not know the distinction between cognitive subject and cognized objects. Understanding is the production of inter-action and inter-edification between Dasein or the human being as a being and other entities as beings.

\section{References}

[1] Heidegger, Martin. "Being and Time: Introduction" in Martin Heidegger: Basic Writings, David Farrell Krell (ed. \& trans.) London: Harper Collins Publisher, Inc., 1993.

[2] Heidegger, Martin. Being and Time. John Macquarrie \& Edward Robinson (trans.) China Social Sciences Publishing House Chengchengh Books Ltd., 1999.

[3] Holdcroft, David. Saussure: Signs, System, and Arbitrariness. New York: Cambridge University Press, 1991.

[4] Holmes, James S. Translated! Papers on Literary and Translation Studies. Beijing: Foreign Language Teaching and Research Press, 2007 